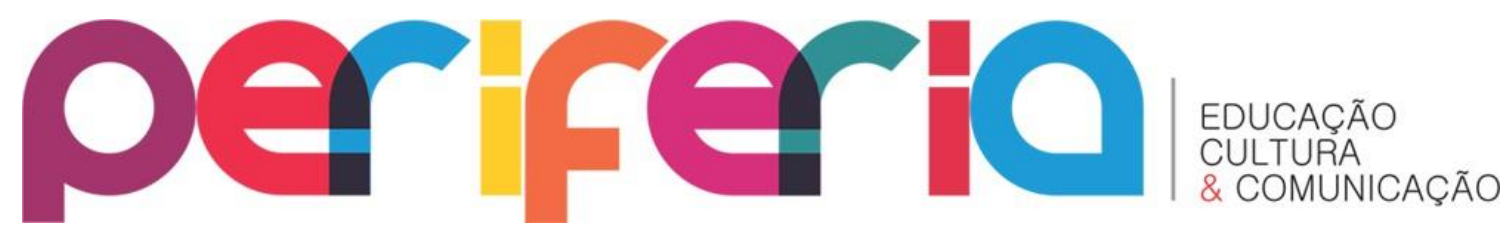

\title{
INTERCULTURALIDADE E EDUCAÇÃO DAS RELAÇÕES ÉTNICO-RACIAIS: REFLEXÕES SOBRE A APLICAÇÃO DA LEI 11.645/08 NO RIO GRANDE DO SUL
}

\author{
Carla Beatriz Meinerz ${ }^{1}$ \\ Universidade Federal do Rio Grande do Sul \\ Claudia Pereira Antunes ${ }^{2}$ \\ Universidade Federal do Rio Grande do Sul \\ Maria Aparecida Bergamaschi ${ }^{3}$ \\ Universidade Federal do Rio Grande do Sul
}

\section{RESUMO}

O artigo analisa os movimentos de aplicação da Lei 11.645/08 na educação básica do Rio Grande do Sul, a partir da descrição de ações de implementação: o Grupo de Trabalho Afro-indígena e o Grupo de Trabalho 26-A. Propõe pensar na lei como uma possibilidade para o diálogo intercultural, e para o repensar da apropriação da temática indígena nas escolas. Discute o conceito de interculturalidade e o princípio da educação das relações étnico-raciais. Evidencia a necessidade de construção de referenciais capazes de embasar currículos interculturais que visibilizem o indígena contemporâneo, e evidenciem as especificidades da formação sociocultural do Rio Grane do Sul.

Palavras-chave: interculturalidade; educação; lei 11.645/08; relações étnico-raciais.

\section{INTERCULTURALITY AND EDUCATION OF ETHNIC-RACIAL RELATIONS: REFLECTIONS ON ENFORCEMENT LAW 11.645/08 IN RIO GRANDE DO SUL ABSTRACT}

This paper analyzes the application of Law 11.645 /08 in basic education of Rio Grande do Sul, from the description of implementation actions: the Afro-indigenous Working Group and the Working Group 26-A. proposes to think of the law as an opportunity for intercultural dialogue and to rethink the appropriation of indigenous subject in schools. Discusses the concept of interculturality and education of ethnic-

\footnotetext{
${ }^{1}$ Doutora e mestre em Educação pela Universidade Federal do Rio Grande do Sul (UFRGS). Licenciada em História pela UFRGS. Integrante do LHISTE - Laboratório de Ensino de História e Educação. Professora adjunta do Departamento de Ensino e Currículo e do Programa de Pós-Graduação em Educação da UFRGS. E-mail: carlameinerz@gmail.com

${ }^{2}$ Mestre em Educação pela Universidade Federal do Rio Grande do Sul. Licenciada em Ciências Sociais pela Universidade Federal do Rio Grande do Sul. Integrante do Grupo de Trabalho Institucional, GT 26-A. Técnica em Assuntos Educacionais da Faculdade de Educação da Universidade Federal do Rio Grande do Sul. E-mail: claudia.antunes.poa@gmail.com

3 Doutora em Educação, professora na Graduação e na Pós-Graduação da Faculdade de Educação da Universidade Federal do rio Grande do Sul - Brasil. Desenvolve pesquisas sobre educação indígena Kaingang e Guarani, tendo várias publicações sobre o tema. E-mail: cida.bergamaschi@gmail.com
} 


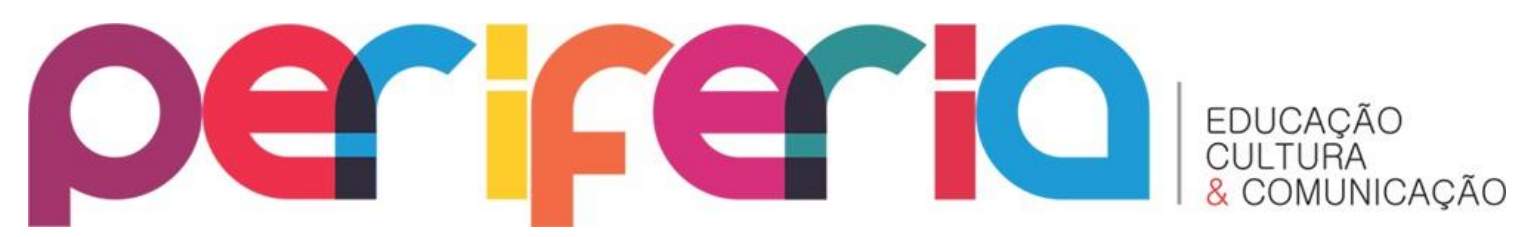

racial relations. Evidences the need for referential construction able to support intercultural curricula that show the contemporary indigenous and showing the specificities of cultural formation of the Rio Grande do Sul.

Keywords: interculturalism; education; ethnic-racial relations.

\section{INTERCULTURALIDADE E EDUCAÇÃO DAS RELAÇÕES ÉTNICO-RACIAIS: REFLEXÕES SOBRE A APLICAÇÃO DA LEI 11.645/08 NO RIO GRANDE DO SUL}

O estudo da história e da cultura indígena na escola está regulamentado por uma lei federal. Trata-se da Lei no $11.645 / 2008$, que cria a obrigatoriedade do ensino da história e da cultura dos povos indígenas nos estabelecimentos de Ensino Fundamental e Médio do país. Podemos perguntar: por que uma lei para obrigar esse estudo? Adianta haver uma lei que cria a obrigatoriedade se são poucos os professores preparados para levar adiante esse estudo com a abordagem que merece? $\mathrm{O}$ ensino da história e da cultura indígenas nas escolas de ensino fundamental e médio previstos na lei é um caminho no sentido da educação intercultural? Essas e outras perguntas ocorrem cada vez que abordamos a temática indígena e sua relação com a escola, o que, hoje, se configura como uma preocupação nos meios escolares e acadêmicos.

Nestor Garcia Canclini (2007), pensador que tem se ocupado com o tema da interculturalidade, diz que os indígenas são hoje os povos mais preparados para o diálogo intercultural. Afirma que os povos ameríndios construíram um "patrimônio para a interculturalidade", referindo-se aos conhecimentos constituídos historicamente e que resultam, por exemplo, em conhecer ao menos uma língua nacional para estabelecer, de fato, o diálogo com outras sociedades, em transitar entre saberes tradicionais e modernos, em lidar com economias de mercado e manter valores próprios da economia da reciprocidade, entre outras possibilidades. $\mathrm{O}$ autor faz pensar que interculturalidade não é só se dispor ao diálogo com o outro, mas é, também, lançar mão de conhecimentos e saberes desse outro que permitam estabelecer e qualificar o diálogo. Assim como uma sociedade, um povo constitui um patrimônio cultural que compreende o conjunto dos bens materiais e imateriais constituídos historicamente e que se referem às identidades e às memórias coletivas 


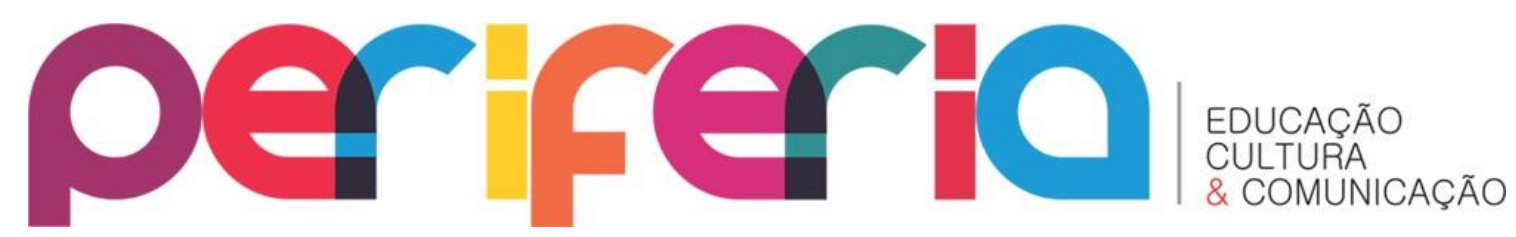

do grupo. O patrimônio para a interculturalidade refere-se aos bens materiais e imateriais que, historicamente, o grupo constituiu para dialogar com outras culturas, como o exemplo citado anteriormente, qual seja a prática do bilinguismo ou plurilinguismo entre os indígenas, ou o esforço que envidam para apreender os modos de vida de outros povos.

Podemos, portanto, pensar na lei como uma possibilidade para o diálogo intercultural, que concretamente poderá significar o movimento de diferentes grupos sociais em interação e aprendizagens mútuas, embora conflitual. Como diz Jorge Gasché, esse diálogo não é nada angelical, porque, em geral, envolve relações de dominação/subordinação, e é perpassado pela violência das desigualdades socioeconômicas. Canclini (2007, p. 17) também vai por esse caminho ao explicar interculturalidade como confrontação, e reconhece que, para existir a interculturalidade, é necessário a vontade de compreender, re-conhecer e admitir que todos os grupos culturais se constituem em relação, sugerindo "negociação, conflito e empréstimos recíprocos". Nesse sentido, a relação inter-cultural é um ingrediente importante para as transformações e para novas configurações culturais de todos os grupos humanos.

Levi-Strauss, no livro História de Lince (1993), compara a mitologia ameríndia com outras mitologias e, se detendo nas narrativas que tem a dualidade como central, constata que, para os povos indígenas, o que funda é a diferença (sol e lua, por exemplo), enquanto que, nas narrativas europeias, é o idêntico. Discute um dualismo que busca a complementariedade (complementar e diferente) e a reciprocidade. Faz uma profunda teorização sobre esse tema e constata que a diferença faz parte do modo de vida indígena. Diz ele: "creio que hoje é possível remontar às fontes filosófica e ética do dualismo ameríndio. Esse dualismo se inspira numa abertura para o outro que se manifestou com toda a clareza quando dos primeiros contatos com os brancos, embora estes fossem animados por disposições bem contrárias" (LEVI-STRAUSS, 1993, p. 14). Essa declaração corrobora para mostrar que, no pensamento ameríndio, a interculturalidade é uma perspectiva ontológica. 


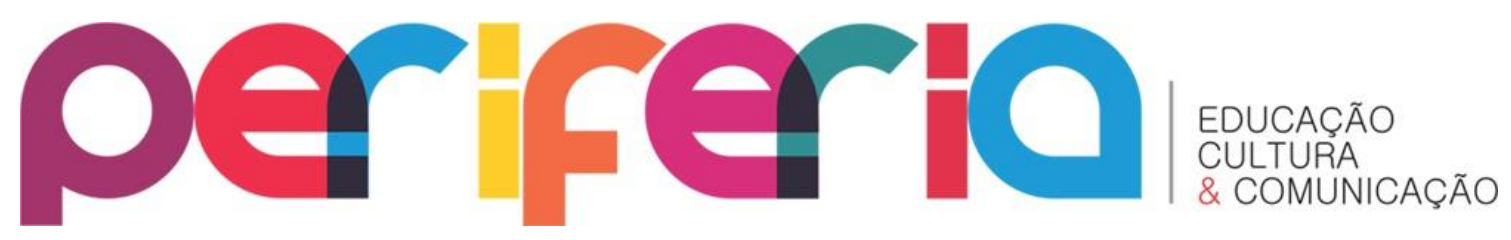

Temos nesses estudos alguns indícios dos movimentos de interculturalidade que os povos indígenas realizam, de abertura para o outro: buscam no outro a complementaridade. Nessa perspectiva, pode-se considerar também a educação escolar, que vem se afirmado a cada dia nas sociedades indígenas. Lembrando que a instituição escolar foi imposta pela colonização, tanto no período colonial, como a implementada a partir do Estado brasileiro, mais especificamente a partir da criação do Serviço de Proteção ao Índio e a Localização dos Trabalhadores Nacionais no início do século XX (SPILT, uma iniciativa que visava integrar os povos indígenas à sociedade nacional). No entanto, a escola também foi apropriada por cada grupo de acordo com suas possibilidades e conveniências, ressignificada mais intensamente a partir da Constituição Federal de 1988, e regulamentada por leis posteriores que, progressivamente, criaram a Escola Indígena Específica e Diferenciada. Essa Escola Indígena que funciona no seio das sociedades ameríndias interage com modos de vida próprios e com a educação da tradição de cada povo. Mas, também estão implementados em seu currículo estudos que visam compreender os modos de vida, línguas e ciências não indígenas e assim, apropriados desses conhecimentos, estabelecer um diálogo mais equitativo com essas sociedades. Parece que esse é um exemplo bastante concreto de educação intercultural e de relações interculturais, que prevê, também, aprender na interação com culturas diferentes.

Se os povos indígenas empreendem esforços para concretizar o diálogo intercultural, nos levam a pensar que, se a proposta educacional é conviver e efetuar trocas com as sociedades indígenas, a escola terá que fazer um esforço para conhecer esses povos, sua história e sua cultura e, mais especialmente, afirmar uma presença que supere a invisibilidade histórica que se estende até o presente. Apesar da colonização, do genocídio, da exploração, da catequização e da tentativa de assimilar os indígenas à sociedade nacional, estes povos mantiveram-se aqui, resistentes, mesmo que, por vezes, silenciosos. Se apresentam fortes, num movimento político de afirmação étnica, mostrando que aqui estão e permanecerão. No contato, a todo o momento são postos à prova quanto às suas identidades étnicas, visto que a 


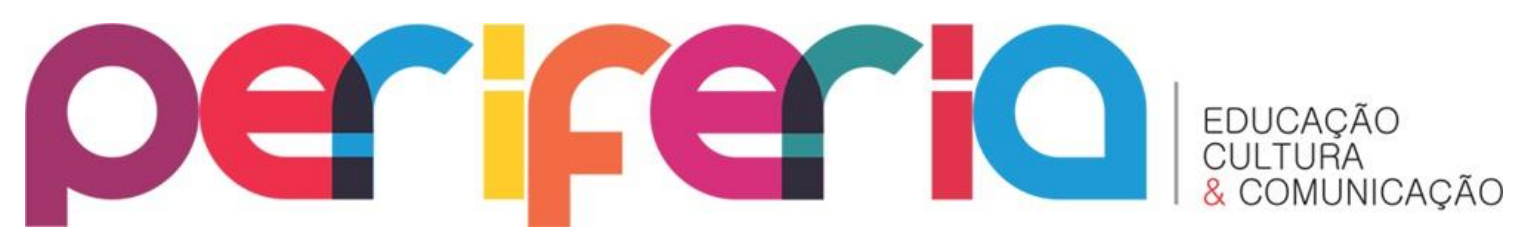

concepção que predomina nas sociedades não indígenas é de povos do passado, não compreendendo que a dinâmica cultural, que é própria de todas as sociedades, faz com que incorporem alguns elementos da cultura ocidental, o que não significa que deixaram de se identificar como indígenas.

Podemos dizer que os movimentos que visam a escolarização, bem como a recente, porém intensa, presença de estudantes indígenas nas universidades, fazem parte de uma luta mais ampla dos povos originários em toda a América, que escolheram a educação escolar como uma aliada nas suas políticas de afirmação étnica, bem como para o diálogo com outras sociedades. Como diz José Bengoa, a emergência indígena de todo o continente americano defende uma educação escolar "intercultural y bilingüe que permita no sólo el conocimiento de la cultura occidental sino también la reprodución de su propria cultura", visando, sobretudo, que seus alunos "se desempeñen adecuadamente, tanto en su sociedad local como en la sociedad nacional de la que son parte" (BENGOA, 2000, pp. 299 e 312).

Concordando com o crescente e visível movimento de afirmação étnica, e contrariando as previsões pessimistas predominantes no século passado, que anunciavam um fim para as sociedades indígenas, iniciamos o século XXI com números que mostram um crescimento populacional ${ }^{4}$ e uma forte presença, protagonizando movimentos e lutas pelos direitos que as colocam em evidência. Se aparecem nos cenários políticos nacionais e internacionais, se lutam por direitos constitucionais em relação à terra, à saúde e à educação, não deixam também de colocar nas pautas de suas preocupações o cuidado necessário que as escolas não indígenas tenham a mão informações mais dignas, apoiadas em conhecimentos respeitosos, e que sua história e sua cultura sejam efetivadas, mudando as concepções preconceituosas e discriminatórias que predominam até então. Na Convenção 169/1989, da Organização

\footnotetext{
${ }^{4}$ Nos dados do IBGE (2010), indígenas autodeclarados compõem 0,4\% da população brasileira, somando cerca de 817.963 mil pessoas. Segundo o censo, populações indígenas podem ser encontradas por todo o território brasileiro, embora mais da metade esteja concentrada na Região amazônica do Norte e Centro-Oeste. Em http://indigenas.ibge.gov.br/graficos-e-tabelas-2, Acessado em 11/05/2014.
} 


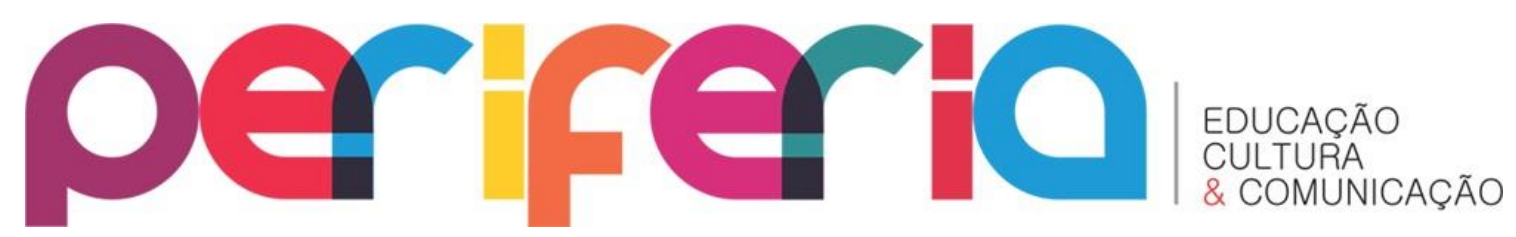

Internacional do Trabalho (OIT) ${ }^{5}$, entre outros itens que falam das relações entre povos indígenas e não indígenas, há em especial o artigo 31, que diz: "Medidas de caráter educativo deverão ser adotadas em todos os segmentos da comunidade nacional [...] com o objetivo de eliminar preconceitos que possam ter com relação a eles". Essa recomendação se dirige em especial à escola, dizendo que "esforços deverão ser envidados para assegurar que livros de história e demais materiais didáticos ofereçam descrição correta, exata e instrutiva das sociedades e culturas dos povos indígenas e tribais" (BRASIL, 2003).

Nesse sentido, observamos uma maior preocupação em compreender e apreender com o outro nas sociedades indígenas: ao mesmo tempo em que nos convocam a conhecê-los, inclusive a partir de uma lei, nos oferecem a possibilidade de encontrar com a nossa ancestralidade. Corrobora com essa assertiva a declaração de Andila Nivygsãnh Inácio, professora kaingang, por ocasião da aprovação da lei 11.645 : "a conquista dessa lei é uma dádiva que os povos indígenas oferecem às escolas não indígenas, para que todos os americanos [portanto, todos nós] tenham a oportunidade de estudar a sua história, a história da sua ancestralidade". Porém, a recíproca nem sempre é verdadeira, principalmente quando observamos o que sucede em nossas escolas e como a temática indígena vem sendo tratada nessa instituição.

\section{A TEMÁTICA INDÍGENA NA ESCOLA}

Esses cuidados que os povos indígenas dispensam com o teor do ensino implementado em nossas escolas estão plenos de razão: estudos efetivados por Zamboni e Bergamaschi (2009) em livros didáticos adotados na primeira metade do século XX mostram que as concepções que predominavam nesses manuais, amplamente usados nas escolas brasileiras, estavam marcadas pelas visões da literatura romântica do século XIX, que mostra o indígena idealizado, representado a um só tempo como herói e vítima, fadado ao extermínio. Derivadas dessas concepções, predominavam nos livros didáticos de história narrativas que abordavam

\footnotetext{
${ }^{5}$ A convenção 169/1989 da OIT foi assinada pelo Brasil no ano de 2003.
} 


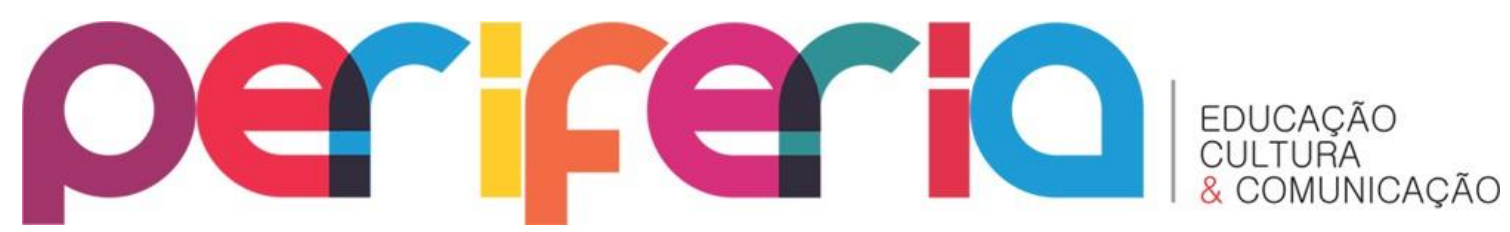

os povos indígenas como representantes do passado, só aparecendo como primeiros habitantes do Brasil, concepções responsáveis pela formação de muitas gerações escolares e, em parte, ainda presentes.

Pensando nessas imagens estereotipadas que os alunos associam aos indígenas, referimos à pesquisa desenvolvida por Gomes (2011) em duas escolas públicas de ensino fundamental das redes estadual e municipal de Porto Alegre, Rio Grande do Sul, que buscou conhecer como está sendo trabalhada a temática indígena nos dias atuais. Entrevistados professores, coordenação pedagógica e alguns alunos - esses inclusive realizaram desenhos para mostrar como representam os povos indígenas -, as respostas não surpreenderam, pois permanecem inseridas em parâmetros já conhecidos $^{6}$.

Nos desenhos das crianças, os indígenas aparecem frequentemente nus, com os corpos pintados e, em geral, em contato com a natureza. Buscando também nos livros didáticos as imagens mais frequentes que retratam os povos indígenas, vemos que a maioria dos manuais os apresentam com pinturas corporais, com cocares nas cabeças e, em geral, sem ou com pouca roupa. Em nenhuma das representações os alunos mostram ter visto imagens nos livros que remetem aos povos indígenas na situação social contemporânea. De fato, as imagens que predominam nos livros são as do indígena na época da colonização, representados por pinturas que confirmam o exótico ou em situações que o vitimiza. Corrobora com estas constatações a afirmação de Coelho, que analisa como a temática indígena está sendo trabalhada na disciplina de História:

[...] uma gritante ambiguidade: enquanto, por um lado, se verifica o redimensionamento do lugar das populações indígenas, na composição dos conteúdos, em tudo atenta às

\footnotetext{
${ }^{6}$ Segundo Zamboni e Bergamaschi (2009), ainda predominam nos livros didáticos de História as seguintes concepções: índio genérico, que nega a diversidade de povos; índio exótico, bárbaro; índio romântico, vinculado à idéia do bom selvagem; índio fugaz, que anuncia um fim inexorável; índio vitimizado, pobre; índio que só aparece no dia do índio, ou na pré-história; e em alguns casos, o indígena histórico, concepção mais recente que enfatiza a historicidade das sociedades indígenas, as suas dinâmicas culturais.
} 


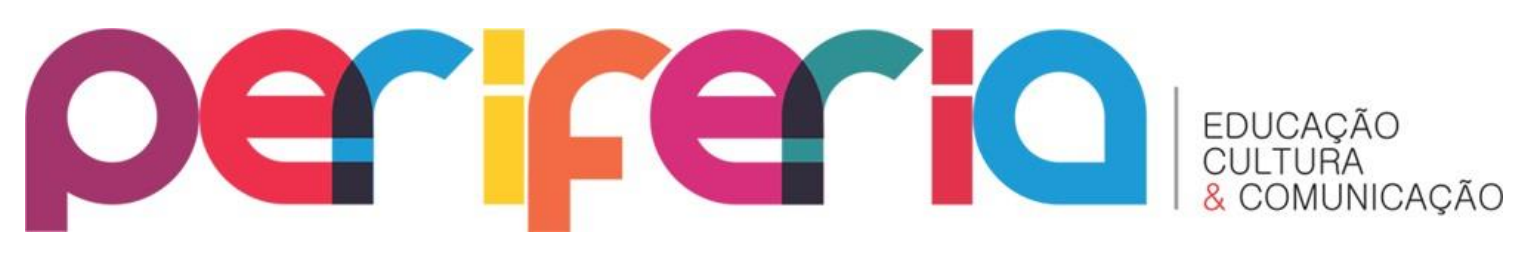

pesquisas mais recentes; por outro lado, se nota a permanência de aportes que se aproximam daquela antiga vocação: as populações indígenas são representadas conforme aquela cultura histórica que os via como ingênuos, vítimas dos colonizadores, cujo traço cultural fundamental era, fora a preguiça, a relação com a natureza. (COELHO, 2010, p. 6)

Embora nas imagens de índios apresentadas pelos livros didáticos predomine um ser do passado, ignorando a forma como vivem atualmente, muitas crianças reconhecem que há índios convivendo conosco na cidade e que estão presentes em vários locais de muita circulação, especialmente para a venda de artesanato. As respostas apontaram para um reconhecimento da presença indígena em algumas cidades litorâneas, no centro da cidade de Porto Alegre ou no Parque da Redenção, na tradicional feira de artesanato que ocorre nos finais de semana. Esses alunos sabem que os indígenas contemporâneos seguem outro estilo de vida, que necessitam vender artesanato e comprar suprimentos para o seu dia a dia. Porém, ainda têm pouco a falar sobre a história e a cultura desses povos, principalmente para reconhecer as singularidades de cada etnia. É importante ressaltar que nem sempre é dada a importância devida a este tema na escola, trabalhado, em geral, somente próximo ao Dia do Índio e de forma superficial e descontextualizada, como apontaram os relatos dos professores (GOMES, 2011).

Neste sentido, a Lei Federal n. 11.645/2008 constitui um importante instrumento para a mudança dessa realidade. Ela coloca para os não indígenas a responsabilidade de construir um patrimônio de interculturalidade, para que, assim como os povos indígenas, se preparem para o encontro e o convívio com o diferente. Esse é um movimento que precisa acontecer dos dois lados, diz Ibañez Caselli:

No obstante, no podemos considerar que ésta sea una práctica intercultural cuando es sólo el docente y los niños indígenas quienes están insertos en esta modalidade. Es decir, la sociedad hegemónica - a la que los niños deben enfrentar no recibe una educación intercultural. (CASELLI, 2009, p. 140). 


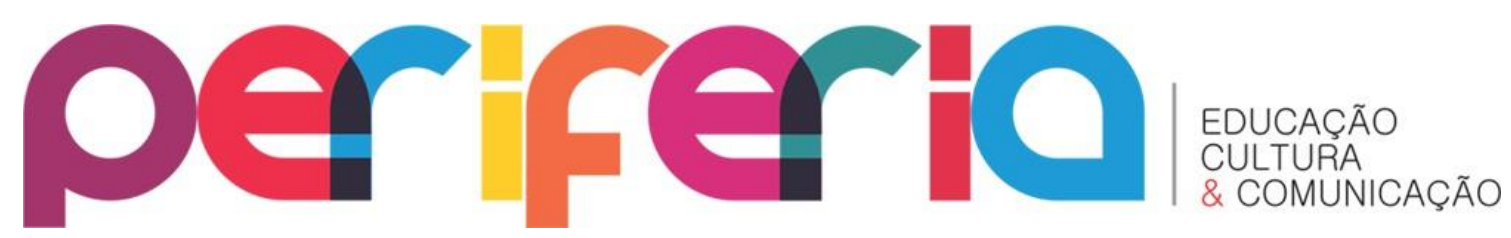

De outro lado, sua aplicação é um grande desafio para as escolas e os professores não indígenas, que não contam com referenciais pedagógicos consolidados para a abordagem dessa temática. Por isso, estes também têm a responsabilidade de desenvolver pesquisas e elaborar materiais didáticos para utilizar em sala de aula. Diga-se de passagem, a maior parte dos professores da educação básica no país não apenas carece de formação para trabalhar com esta temática, como foi formada uma perspectiva histórico-cultural que invisibilizou os povos indígenas e sua participação na formação social brasileira, no presente e no passado.

\section{MOVIMENTOS DE IMPLEMENTAÇÃO E APLICAÇÃO DA LEI 11.645 NO RIO GRANDE DO} SUL

Conforme dados do Censo de 2010 do Instituto Brasileiro de Geografia e Estatística 7 , o estado do Rio Grande do Sul é formado por 497 municípios e tem uma população de cerca de 10,7 milhões de habitantes. Essa população vive predominantemente no meio urbano, representando $85,1 \%$ nessas localidades. Quanto ao quesito cor ou raça, a mesma pesquisa apontou que $83,22 \%$ da população se autodeclarou branca, $16,14 \%$ parda ou preta, $0,33 \%$ amarela e $0,31 \%$ indígena. No que refere ao sistema estadual de ensino, dados da Secretaria Estadual de Educação ${ }^{8}$ informam que, em 2010, o estado contabilizou 9.841 estabelecimentos de ensino da educação básica, sendo $77,7 \%$ da rede pública e o restante da rede privada. No mesmo, ano foram matriculados nestes estabelecimentos cerca de 2,5 milhões de estudantes, sendo $86 \%$ deles em instituições públicas de ensino, e $62 \%$ no ensino fundamental.

Neste contexto de uma população que majoritariamente se identifica como branca, ainda que estudos venham evidenciando significativa contribuição ameríndia

\footnotetext{
${ }^{7}$ www.ibge.gov.br, acesso em 11/05/2014.

8 Secretaria de Estado da Educação do Rio Grande do Sul. Diagnóstico da Educação Básica no Rio Grande do Sul com Ênfase no Ensino Médio 2010. http://www.educacao.rs.gov.br/dados/diagnostico relatorio final 2010.pdf, acesso em 11/05/2014.
} 


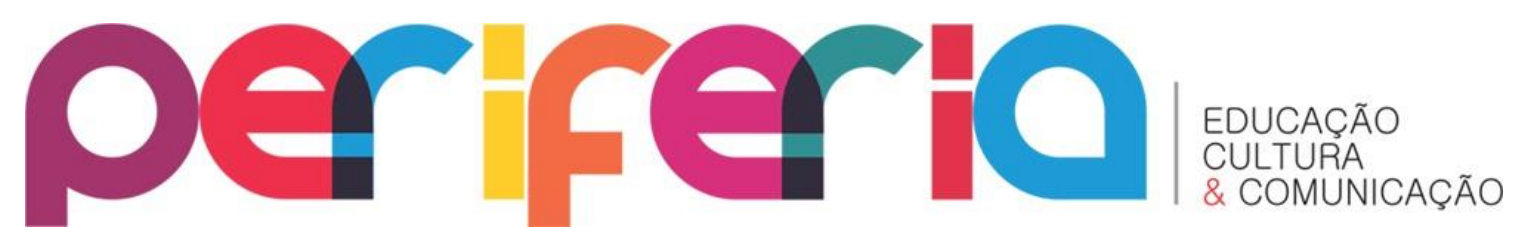

no perfil genético da população do Rio Grande do Sul $^{9}$ (KENT e SANTOS, 2012), e onde predominam concepções que desvalorizam e/ou invisibilizam a presença e os modos de vida nativos na formação sociocultural da região, vêm se constituindo movimentos de implementação da Lei e de sua congênere, a Lei $10.639 / 2003^{10}$, bem como de acompanhamento deste processo. Embora ainda não haja levantamentos publicados sobre a aplicação da Lei em nível estadual, é possível supor que boa parte dos esforços neste sentido vem sendo envidada individualmente por professores, e institucionalmente por universidades que oferecem formação continuada para uma pequena parcela do corpo docente da educação básica. Um exemplo disso é o Curso de Aperfeiçoamento UNIAFRO - Política de Promoção da Igualdade Racial na Escola 1a ed., oferecido pela Faculdade de Educação da UFRGS em parceria com o MEC, na modalidade à distância, com oferecimento de 120 vagas em 2013 e 167 vagas em 2014.

Em outro plano, duas experiências em curso buscam promover a aplicação da Lei em nível estadual. O Grupo de Trabalho de elaboração do Plano Estadual das Diretrizes Curriculares Nacionais para a Educação das Relações Etnicorraciais e para o Ensino das Histórias e das Culturas Afro-Brasileiras e Indígenas, GT Afro indígena, foi criado pelo governo do estado através do Decreto № 50.725, de 9 de outubro de 2013. O Decreto estabeleceu, ainda, um prazo de seis meses para a criação do referido plano. Conforme o mesmo documento, o GT é composto por representantes de órgãos, entidades e conselhos estaduais, em sua maioria de cunho governamental.

Outra iniciativa vem sendo levada a cabo pelo Grupo de Trabalho 26-A, constituído no primeiro semestre de 2013 por representantes do Tribunal de Contas do Estado, Ministério Público Estadual, Defensoria Pública da União/RS, Universidade Federal do Rio Grande do Sul, Rede Afro-Gaúcha de Profissionais do Direito, pesquisadores e professores convidados. Este Grupo de Trabalho visa contribuir para a

\footnotetext{
${ }^{9}$ Conforme Kent e Santos (2012), estudo genético coordenado pela pesquisadora Maria Cátira Bortolini durante a década de 2000 apontou a existência de proporção de 36\% de DNA mitocondrial indígena na amostra geral da população do Rio Grande do Sul avaliada.

${ }^{10}$ A Lei 10.639, aprovada em 9 de janeiro de 2003, estabeleceu a obrigatoriedade do ensino da história e cultura afro-brasileira nas escolas de ensino fundamental do país.
} 


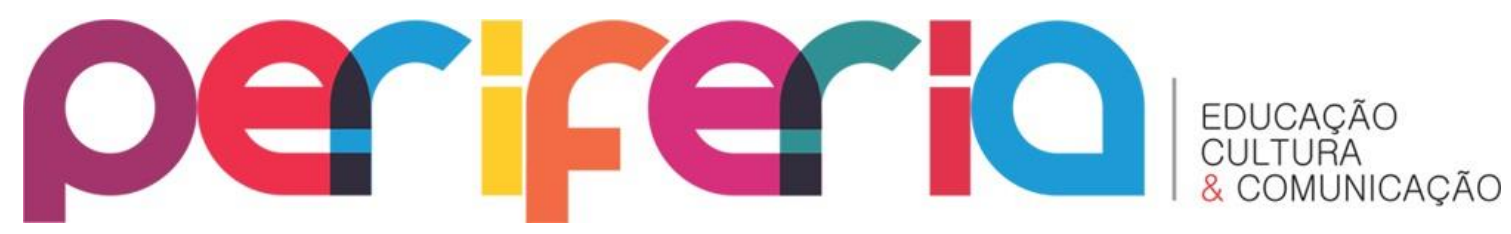

criação de mecanismos de fiscalização e monitoramento da aplicação das Leis 10.639/2003 e 11.645/2008 no sistema estadual de ensino, bem como vem oferecendo subsídios à construção de uma ação fiscalizatória a ser realizada pelo Tribunal de Contas do Estado junto aos municípios gaúchos ${ }^{11}$. Conforme Jorge Terra,

A ideia matriz do GT 26-A é a de que já houve tempo suficiente para as entidades públicas e privadas terem ciência, compreensão e sensibilização sobre o direito de os alunos do ensino fundamental e médio terem acesso à história e à cultura afro-brasileira e indígena. Ademais, a produção de material didático e de outras ordens, bem como a disponibilização de cursos acessíveis individualmente aos professores não levaram ao resultado necessário, esbarrandose na inação sistemática de gestores. (TERRA, 2013, p.1).

No ano de 2013, este Grupo de Trabalho realizou a análise de dados de questionários respondidos por mais de 60 municípios gaúchos sobre a implementação das referidas Leis nas escolas municipais. Os questionários foram encaminhados pelo Ministério Público de Contas aos municípios no ano de 2012, com o intuito de subsidiar a criação de instrumentos de fiscalização da aplicação das Leis. No âmbito das atividades do GT 26-A, a Defensoria Pública da União/RS também realizou estudo sobre a implementação das Leis nas instituições federais de ensino básico e profissionalizante no estado. Dado o pioneirismo desses estudos, o Grupo de Trabalho sinalizou a possibilidade de futura publicação desses dados ${ }^{12}$. Desde 2014, o GT vem atuando no desenvolvimento de capacitações sobre a implementação das Leis a serem oferecidas para prefeitos e secretários municipais de educação e para auditores do Tribunal de Contas do Estado.

\footnotetext{
${ }^{11}$ Disponivel em

http://www1.tce.rs.gov.br/portal/page/portal/tcers/administracao/gerenciador de conteudo/noticias/ TCE-

RS\%20promove\%20semin\%E1rio\%20sobre\%20Lei\%20de\%20Diretrizes\%20e\%20Bases\%20da\%20Educa \%E7\%E3o, acessado em 11/04/2014.

12 Conforme notícia publicada no site da Defensoria Pública da União em 19 de junho de 2013. Disponível

http://www.dpu.gov.br/index.php?option=com content\&view=article\&id=15339:encontro-discute-oensino-de-historia-e-cultura-afro-brasileira-e-indigena-na-rede-de-ensino-basica-nors\&catid=79\&ltemid=220, acessado em 11/05/2014.
} 


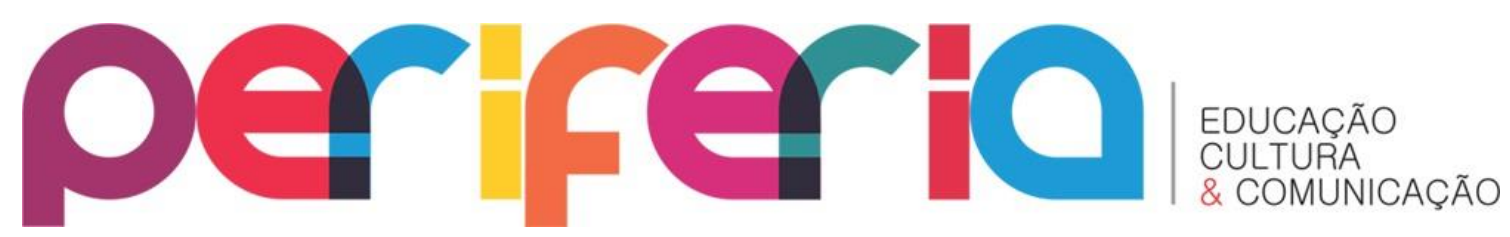

Iniciativas como estas representam um importante passo na implementação das Leis $10.639 / 2003$ e 11.645/2008 no estado, especialmente porque tencionam o poder público a atuar efetivamente na sua aplicação, respaldando e criando condições para a atuação dos professores neste sentido. De outro lado, muito se tem a avançar na inserção e qualificação da abordagem dessas temáticas em sala de aula, pois, conforme dito anteriormente, a construção do diálogo intercultural é perpassada por conflitualidades e relações de desigualdade. Neste sentido, pensar essa construção no estado também envolve refletir sobre a educação das relações étnico-raciais no país como um todo.

\section{INTERCULTURALIDADE E EDUCAÇÃO DAS RELAÇÕES ÉTNICO-RACIAIS: CONEXÕES ENTRE PESQUISA E MOVIMENTOS DE IMPLEMENTAÇÃO DO ARTIGO 26-A}

Reforçamos que a interculturalidade, no caso brasileiro, passa por ações mais intensas no sentido da construção de um contexto de equidade capaz de compor as premissas do reconhecimento do direito do outro no diálogo entre diferentes culturas. Segundo Neusa Vaz e Silva,

É necessário que se tome com seriedade as culturas, ou seja, reconhecê-las e respeitá-las em seu direito de ter mundo próprio e principalmente não serem impedidas por coerção em suas possibilidades de desenvolvimento real. Tal direito foi negado totalmente às culturas originárias das Américas, à época da colonização e ainda hoje em alguns processos "civilizatórios", não oferecendo condições, ou até mesmo, promovendo a anulação da capacidade para pensar, ver, sentir, organizar e reproduzir o que o povo compreende como seu mundo. Não é oportunizada a possibilidade de que as culturas modelem sua materialidade desde seus próprios valores e metas. E, na verdade, as relações entre as culturas devem processar-se com base na observação prática do direito de cada cultura ser si mesma. (SILVA, 2009, p. 44)

Avançamos muito. Porém, precisamos reconhecer que ainda vivemos numa sociedade marcada pela desigualdade, também do ponto de vista étnico-racial. Lutamos por um diálogo marcado pela presença concreta do outro em nossas 


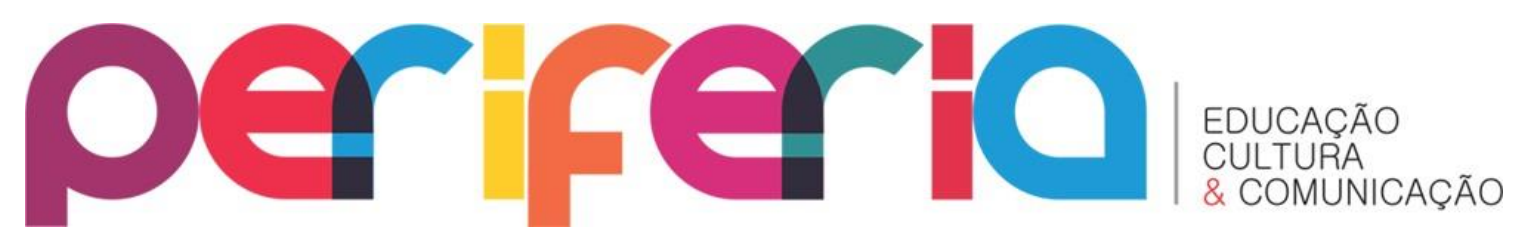

instituições sociais. Por isso, nosso compromisso como pesquisadoras é atuar também com ações como a do GT 26-A relatadas acima.

O processo inédito que o GT 26-A vem construindo ao consolidar um movimento de auditoria sobre os gestores na aplicação do artigo 26-A da LDBEN é fundamental, pois constrói um novo momento no entendimento do que seja enfrentar as desigualdades étnico-raciais no Brasil. Essa novidade está relacionada com o fato de que se busca incidir sobre a ineficiência dos gestores na aplicação das Leis relativas ao enfrentamento desses temas sensíveis ou controversos, como é o caso das relações étnico-raciais. Basta acompanhar as repercussões de denúncias e de processos judiciais relativos às práticas de racismo para perceber as dificuldades de lidar com o acirramento das tensões de origem étnico-racial no cotidiano das relações sociais em nosso país. Apesar dos compromissos internacionais assinados pelo Estado brasileiro, das políticas afirmativas correlatas e das legislações específicas, há um contexto de ineficiência no combate a essas práticas criminosas. Pensadores como Jorge Terra, Procurador do Estado do Rio Grande do Sul, afirmam que estamos vivendo um cenário de racismo institucional, consolidado através da menorização ou desatenção aos interesses de determinados grupos étnicos, contribuindo para a permanência da discriminação. No texto $O$ racismo institucional no combate ao racismo, Jorge Terra afirma que o exame do preconceito e da discriminação racial não se calca no sentir e no agir individual - sobretudo em uma sociedade que não se admite racista e que ainda sustenta conformar uma democracia racial -, mas nos padrões de conduta, nos posicionamentos, nas composições institucionais e nos resultados práticos para o grupo lesado ${ }^{13}$.

Para consolidar o diálogo intercultural parece que precisamos estar diante do outro em sua concretude, e isso significa romper com as especificidades históricas do jeito como nos relacionamos entre nós mesmos, com nossas distintas culturas, etnias, jeitos de viver e de pensar. O que então caracteriza a especificidade das relações

\footnotetext{
${ }^{13}$ Texto na íntegra em: http://estadodedireito.com.br/tag/jorge-terra/
} 


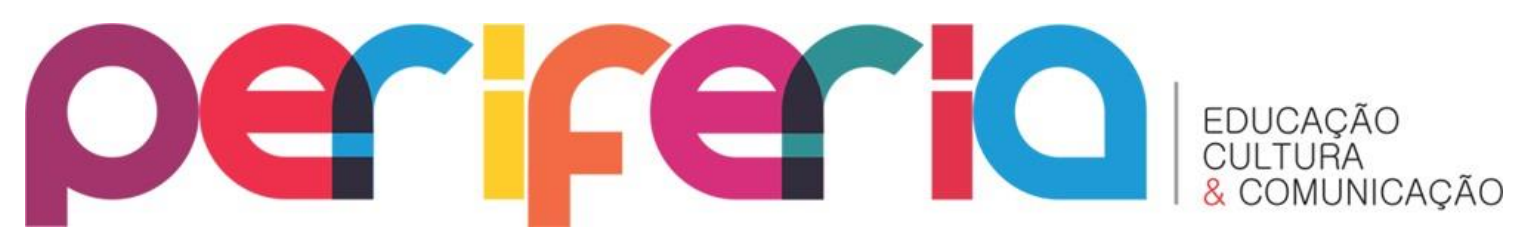

étnico-raciais no Brasil? Os estudos de Lília Moritz Schwarcz (1998) demonstram que o racismo no Brasil, historicamente, afirma-se na intimidade e na informalidade, ao mesmo tempo que o mito da boa convivência e da democracia racial consolida-se na representação do que seja ser brasileiro. Para a autora, as especificidades de nossa história na perspectiva das relações étnico-raciais "fez da desigualdade uma etiqueta internalizada e da discriminação um espaço não formalizado" (SCHWARCZ, 1988, p.184).

Talvez resida aí parte das contradições trilhadas na aplicação e recepção das Leis e políticas que tencionam tais imaginários, mentalidades e práticas culturais nos espaços escolares: o fato de que, em geral, não reconhecemos publicamente a existência da desigualdade racial. A escola, como espaço público, vive os dilemas da consolidação desse difícil enfrentamento das práticas racistas, discriminatórias e preconceituosas, uma vez que, como espaço sociocultural, tende a reconstruir a informalidade pautada na desigualdade a partir da racialidade. Por isso, o tema da educação das relações étnico-raciais é fundamental. Se pensarmos que os preconceitos se materializam através de atos discriminatórios, e que são aprendidos nos processos de socialização, onde a escola tem papel fundamental, devemos tratar com vigor essas temáticas na educação formal.

Parece importante, nessa perspectiva, reconhecer que o contexto inaugurado com a promulgação das Leis 10.639/03 e 11.645/08, inserido no conjunto das políticas afirmativas para a promoção da igualdade racial, é historicamente inovador ao trazer, para o embate público via educação escolar, as práticas do racismo, do preconceito e da discriminação, tradicionalmente negadas ou mantidas no plano privado. No campo da Educação, a inovação se anunciou com força, convocando os gestores e professores a um redimensionamento de suas políticas e de suas práticas educacionais, capaz de fundamentar uma educação das relações étnico-raciais balizada pela promoção de ações e reflexões fundadas em critérios de justiça social e cidadania.

Por outro lado, é preciso atentar para o fato das Leis trazerem ao universo cotidiano das ações educativas a presença de temáticas sensíveis e controversas. Do 


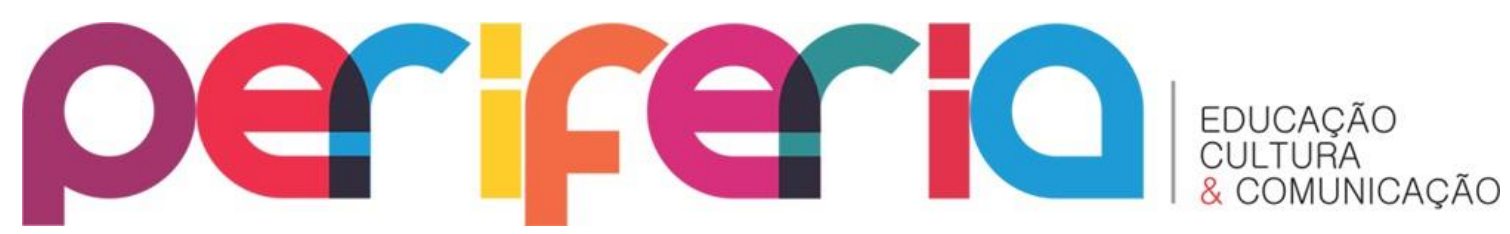

professor exige-se um enfrentamento reflexivo e fundamentado sobre questões sensíveis e não resolvidas socialmente, como por exemplo os temas relativos ao preconceito étnico-racial.

Os professores, por demandas sociais colocadas na forma da Lei, estão diante de uma nova responsabilidade social: estudar, ensinar e dialogar com as raízes históricas e filosóficas, ou, ainda, com as visões de mundo, originariamente indígenas, hoje expressas como heranças das ancestralidades daqueles que, nesse território, construíram e reconstruíram suas vidas e seus pertencimentos étnicos. Tais narrativas não privilegiam uma única maneira de ser e de estar no mundo como referência e padrão, mas exploram as diferenças na perspectiva do diálogo e da pluralidade.

Uma pesquisa em andamento sobre a recepção das Leis 10.639/03 e 11.645/08 nas trajetórias de professores de História do Rio Grande do Sul ${ }^{14}$ demonstra que o encaminhamento dessa legislação tem sido resultado de projetos mais pessoais do que coletivos, geralmente construídos por profissionais que já tem determinação política e afetiva em relação às questões da desigualdade étnico-racial. A coleta de dados realizada no município de Cachoeirinha/RS reafirma essa premissa: ainda é o que chamamos de afeto à causa o que diferencia e condiciona a recepção do artigo 26-A, o estudo de histórias e culturas africanas, afro-brasileiras e indígenas nas aulas de História ou de outros campos disciplinares na escola. Ao mesmo tempo, os processos de recepção das Leis são marcados por imperativos morais e de ressentimentos, que podem impor pautas de construção de outras narrativas da história, com menos diálogo com a historiografia, criando novas estereotipias e menos pluralidades. A questão é que estamos tratando de um movimento de obrigatoriedade curricular, onde a resistência ao estudo dessas temáticas ainda impera, inclusive nas experimentações da Educação Superior ${ }^{15}$. Por isso, é urgente movimentos de

\footnotetext{
${ }^{14}$ Projeto de pesquisa coordenado por Carla Beatriz Meinerz, intitulado Trajetórias da educação das relações étnico-raciais no Rio Grande do Sul: ensino de História e recepção das leis 10.639/03 e 11.645/08, em andamento e com aprovação na Comissão de Pesquisa da Faculdade de Educação da UFRGS (COMPESO/EDU).

${ }^{15}$ A pesquisa está realizando um mapeamento dos currículos dos cursos de História em Instituições de Ensino Superior no Rio Grande do Sul. Detecta-se que, nesses currículos, também podemos ver a não
} 


\section{periferio}

auditorias que co-responsabilizem os gestores públicos vinculados às políticas de educação, como é o caso do processo acompanhado pelo GT 26-A.

\section{CONSIDERAÇÕES FINAIS}

A abordagem da história e cultura dos povos indígenas e da África e das populações afro-brasileiras na sala de aula, como preconiza o Artigo 26-A, mexe com aspectos profundos e cristalizados nas relações étnico-raciais no Brasil, trazendo ao universo da escola a presença de temáticas sensíveis e não resolvidas socialmente, como o preconceito étnico-racial. Também traz desafios da ordem da gestão dos estabelecimentos e sistemas escolares que, no caso do Rio Grande do Sul, fazem com que sua aplicação fique, na maior parte das vezes, restrita às iniciativas individuais de docentes sensíveis à temática.

De outro lado, alguns movimentos de implementação da Lei, entre os quais se destaca a atuação inovadora do GT 26-A, trazem nova luz ao caminho a ser percorrido, ao propor estratégias de fiscalização do cumprimento da Lei, acenando com a possibilidade de maior apoio institucional aos professores. Desse modo, se espera que, aos poucos, sejam construídos referenciais que possam embasar currículos interculturais que visibilizem o indígena contemporâneo e evidenciem as especificidades da formação sociocultural no estado, problematizando as relações étnico-raciais e superando uma tendência curricular que privilegia o estudo de uma ancestralidade europeia, representada pelos imigrantes alemães, italianos, portugueses e de outras nacionalidades que seriam responsáveis pelo "povoamento" do solo gaúcho, em detrimento da ancestralidade ameríndia e afro-brasileira.

Ao avançar neste sentido, conforme Gomes, "Temos, então, a possibilidade de entender a presença indígena na nossa sociedade [...] como a herança de uma ancestralidade que colabora nas formas de vida atuais, mesmo que não se reconheça

obrigatoriedade desses temas de estudo, abrindo espaços igualmente para ações individuais de professores universitários afetados pelos mesmos. 


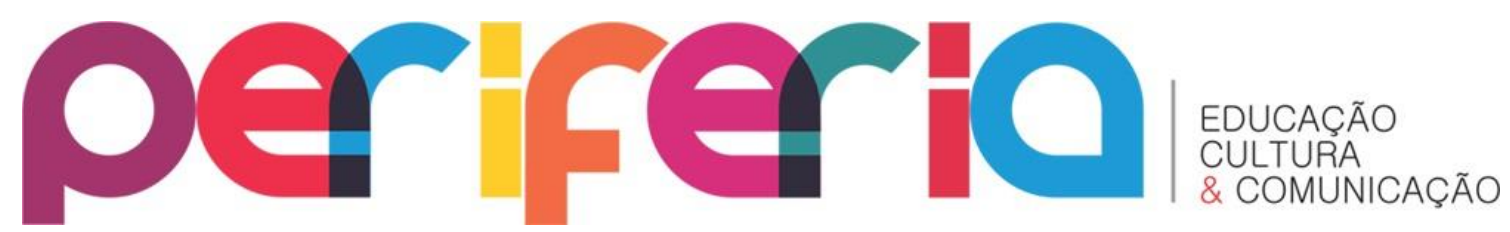

como indígena" (GOMES, 2011, p. 38). Isto representa um desafio, e, ao mesmo tempo, uma potente possibilidade em direção a uma educação intercultural que nos torne capazes de reconhecer e valorizar nossa ancestralidade cultural em suas múltiplas matrizes, bem como nos prepare para o encontro e o convívio com o diferente, a exemplo do que já vêm fazendo os povos indígenas.

\section{REFERÊNCIAS BIBLIOGRÁFICAS}

BENGOA, José. La emergência indígena en América Latina. Santiago, Chile: Fondo de Cultura Económica, 2000.

BRASIL. Convenção no 169 sobre povos indígenas e tribais em países independentes e Resolução referente à ação da OIT sobre povos indígenas e tribais. Brasília: OIT, 2003.

CANCLINI, Néstor García. Culturas Híbridas: estratégias para entrar e sair da modernidade. Tradução de Ana Regina Lessa e Heloísa Pezza Cintrão. São Paulo: EDUSP, 1997.

COELHO, Mauro Cezar. As populações indígenas no livro didático, ou a construção de um a gente histórico ausente. Caxambu: 2007. Disponível em: <http://30reuniao.anped.org.br/ trabalhos/GT13-3000--Int.pdf>. Acesso em 11 de maio de 2014.

GOMES, Luana Barth. Legitimando saberes indígenas na escola. Dissertação de Mestrado. Porto Alegre: UFRGS, PPGEDU, 2011.

IBAÑEZ CASELLI, María Amalia. Políticas públicas y prácticas educativas. TAMAGNO, Liliana (Coord.). In: Pueblos indígenas: interculturalidad, colonialidad y política. Buenos Aires: Biblos, 2009. pp. 129-146.

KENT, Michael; SANTOS, Ricardo Ventura. "Os charruas vivem nos gaúchos": a vida social de uma pesquisa de "resgate" genético de uma etnia extinta no Sul do Brasil. Horizontes Antropológicos, Porto Alegre, Ano 18, n. 37, p. 341-372, jan./jun. 2012.

LÉVI-STRAUSS, Claude. Histórias de Lince. Tradução Beatriz Perrone-Moisés. São Paulo: Companhia das Letras, 1993.

SCHWARCZ, Lília Moritz. Nem preto nem branco, muito pelo contrário: cor e raça na intimidade. In: SCHWARCZ, L. M. (org.) História da Vida Privada no Brasil: contrastes da intimidade contemporânea. São Paulo: Cia das Letras, 1998, vol. 4.

SILVA, Neusa Vaz e. Teoria da Cultura de Darcy Ribeiro e a Filosofia Intercultural. Tese apresentada na Facultad de Postgrados para optar ao grau de Doutor em Filosofia Iberoamiercana na Universidad Centro Americana "JOSE SIMEÓN CAÑAS". San Salvador, El Salvador, 2009.

TERRA, Jorge. A espada aliada à balança. Disponível em http://jorgeterra.wordpress.com 2013/05/05/gt-26-a-a-espada-aliada-a-balanca/. Acessado em 06/05/2013.

ZAMBONI, Ernesta; BERGAMASCHI, Maria Aparecida. Povos Indígenas e Ensino de História: memória, movimento e educação. 17. COLE, 2009. Disponível em: http://www.alb.com.br/anais17/txtcompletos/sem12/COLE 3908.pdf. 